
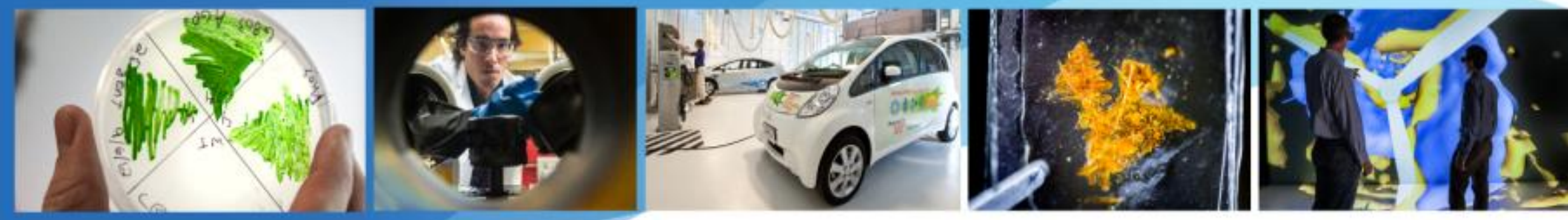

\section{A Practical Irradiance Model for Bifacial PV Modules}

\section{Bill Marion}

Sara MacAlpine, Chris Deline (NREL)

Amir Asgharzadeh, Fatima Toor (University of lowa)

Daniel Riley, Joshua Stein, Clifford Hansen (Sandia)

June 28, 2017

$44^{\text {th }}$ IEEE Photovoltaic Specialist Conference, Washington, D.C.

NREL/PR-5J00-68678

NREL is a national laboratory of the U.S. Department of Energy, Office of Energy Efficiency and Renewable Energy, operated by the Alliance for Sustainable Energy, LLC. 


\section{Introduction}

- Bifacial PV modules use radiation received by both the front and back surfaces, but only irradiance models for the front surface are fully developed and validated.

- This work developed a backside irradiance model and compared model estimates with backside irradiance measurements using reference cells installed on the backside of PV systems at NREL and Sandia. 
- Similar to models for the front side, configuration factors (CFs) are used. (The fraction of irradiance received from a source).

- Irradiance received by ground corrected for shadows and restricted view of the sky using array geometry.

- Irradiance corrected for AOI (beam \& diffuse).

- Irradiances calculated for each row of cells in panel.

- Edge effects not considered.

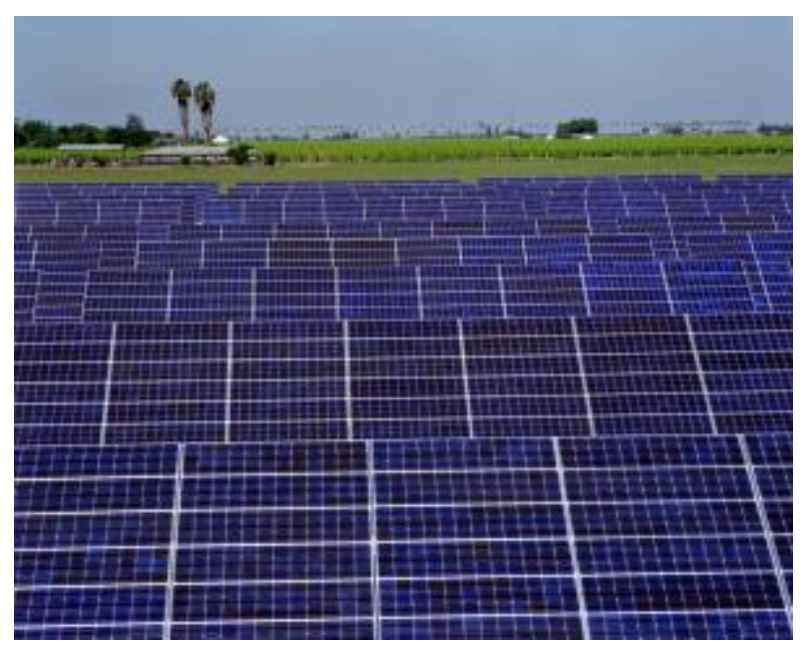


Front Side Sky and Ground-Reflected Irradiance

$$
I_{\mathrm{sky}}=\mathrm{DHI} \cdot(1+\cos \beta) / 2
$$

$I_{\mathrm{r}}=\rho \cdot \mathrm{GHI} \cdot(1-\cos \beta) / 2$



CF 


\section{Backside Sky and Ground-Reflected Irradiance}

- CFs may also be used for the backside

- But only if the irradiance is the same intensity over the field-of-view

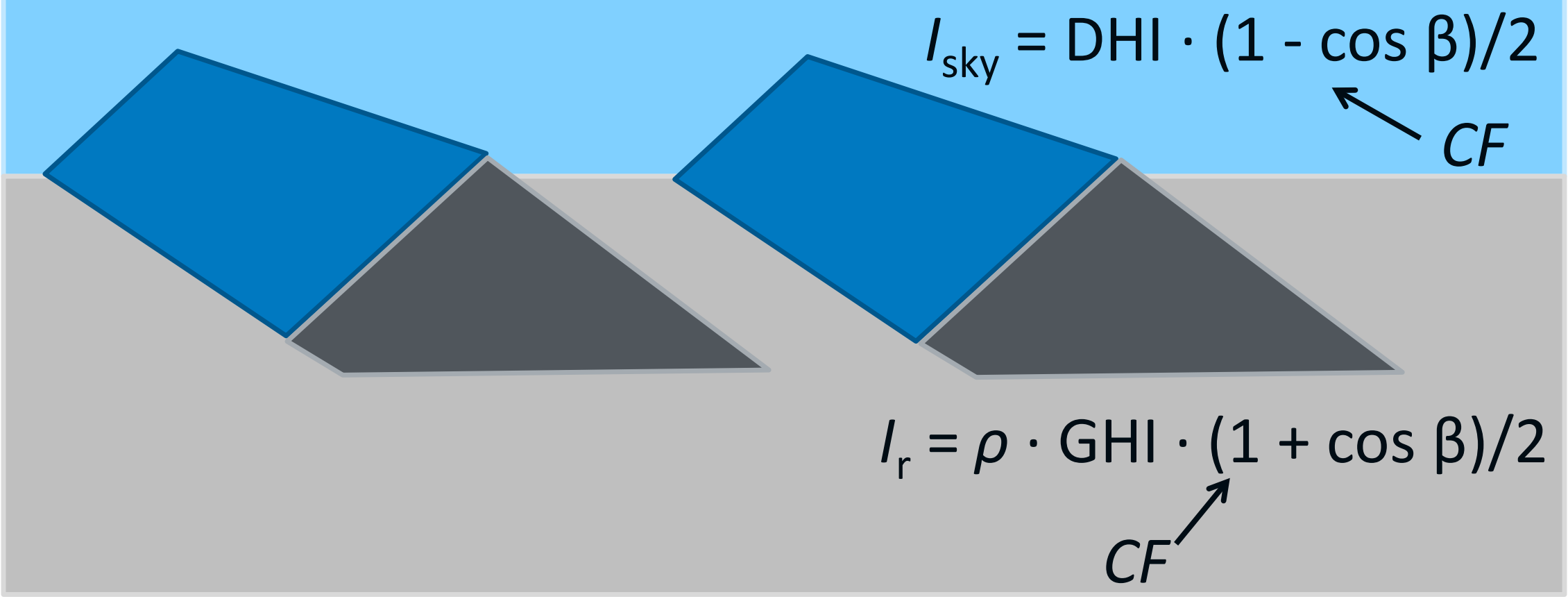


CFs Using Field-of-View Angles

- Permits determining the contribution of each source of irradiance (shaded or unshaded ground, module reflections, etc.)






\section{Irradiance Received by Ground Varies with Location}

- Ground irradiance (GRI) is reduced by shadows and by the array reducing the view of sky

- Calculated at 100 locations in the row-to-row dimension

$\mathrm{GRI}=a \cdot\left(\mathrm{DNI}+I_{\text {cir }}\right)+C F_{\text {sky }} \cdot I_{\text {sky }}$

where:

$a$ is the cosine of the sun zenith angle if the ground segment is unshaded. If shaded, $a$ is the cosine of the sun zenith angle multiplied by the fractional opening of the PV array due to gaps between PV cells and modules. 


\section{$C F_{\text {sky }}$ Depends on Location in Row-to-Row Dimension}

$$
C F_{s k y}=\left(\cos \theta_{\mathrm{S} 1}-\cos \theta_{\mathrm{S} 2}\right) / 2
$$






\section{Calculating the Backside Irradiance (BSI)}

- Summed over $180^{\circ}$

field-of-view using one

degree increments



$\mathrm{BSI}=b \cdot F_{b} \cdot\left(\mathrm{DNI}+I_{c i r}\right)+\sum_{i=1^{\circ}}^{180^{\circ}} C F_{i} \cdot F_{i} \cdot I_{i}$

where $b=$ maximum $(0$, cosine of the AOI of the DNI); $F_{b}$ and $F_{i}$ are $\mathrm{AOI}$ corrections for the beam and diffuse ${ }^{1}$; and $I_{i}$ is the irradiance viewed by the ith one-degree segment (either $I_{\text {sky }} I_{\text {hor }}, \rho \cdot G R I_{n}$, or $I_{\text {refl }}$ ).

${ }^{1}$ B. Marion, "Numerical method for angle-of-incidence correction factors for diffuse radiation incident photovoltaic modules", Solar Energy 147: 344-348, 2017. 
- Model Input - Direct Normal Irradiance (DNI) and Diffuse Horizontal Irradiance (DHI), used with Perez model to derive circumsolar, sky, and horizon diffuse.

- Measured backside irradiances for NREL and Sandia systems.
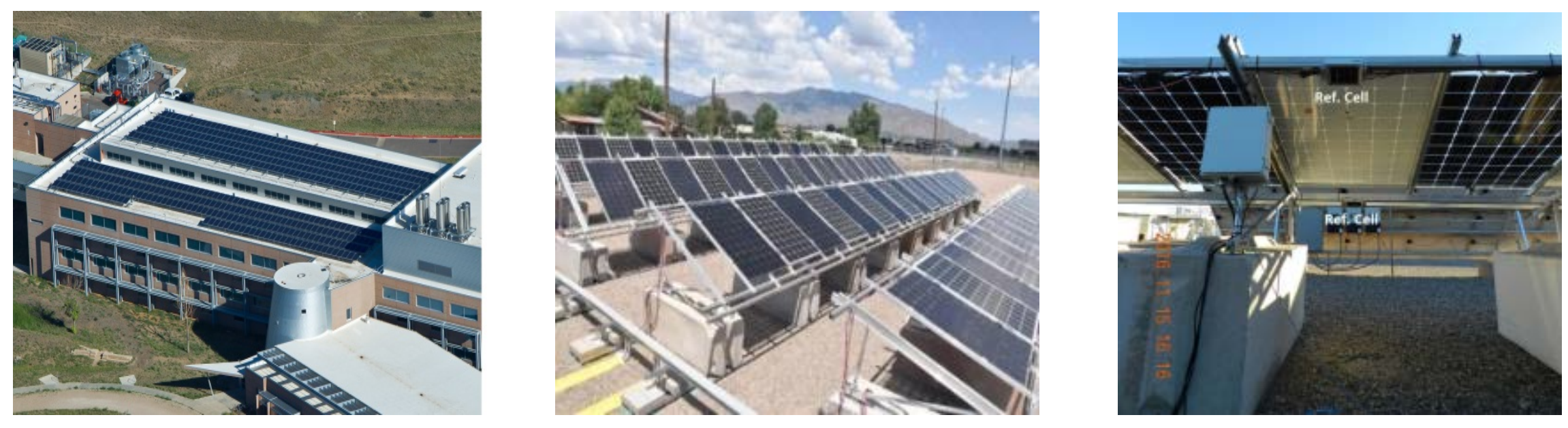


\section{Validation Results - NREL Site}

- Better results for upper roof than for lower roof.

- Off south azimuth shifts BSI peak values.

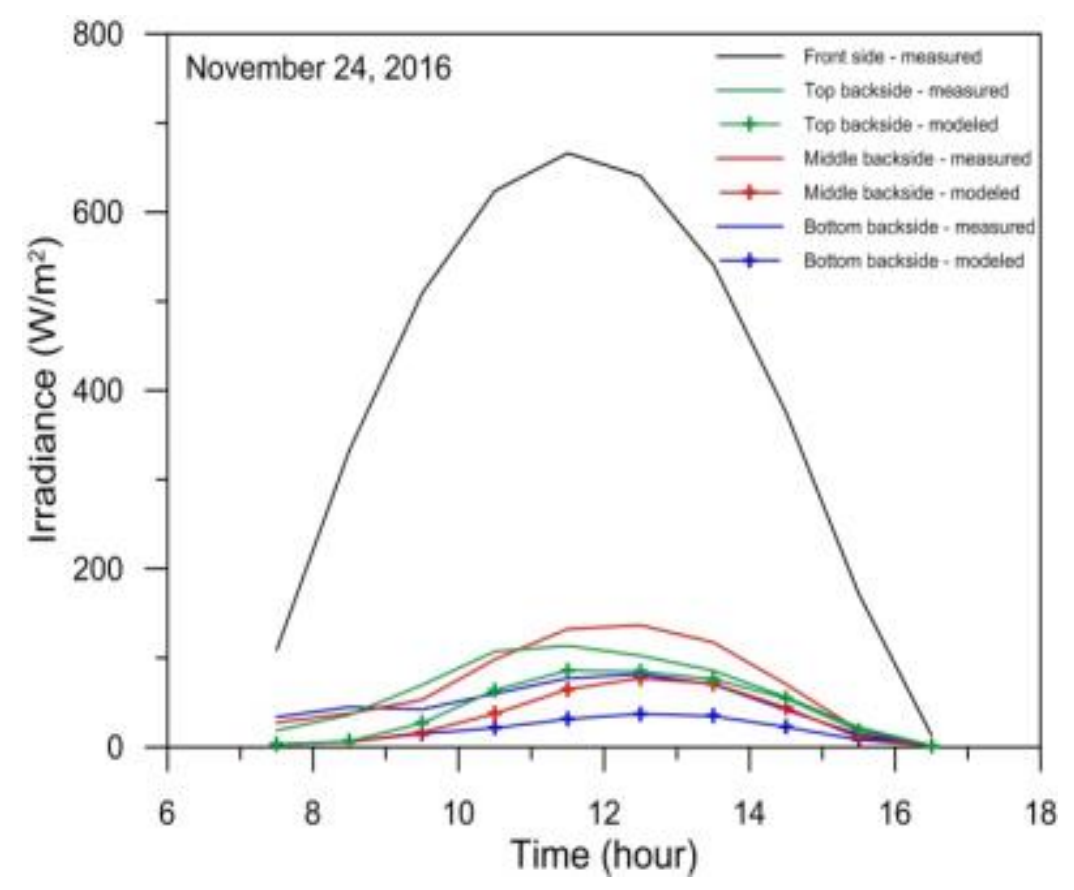

Lower Roof

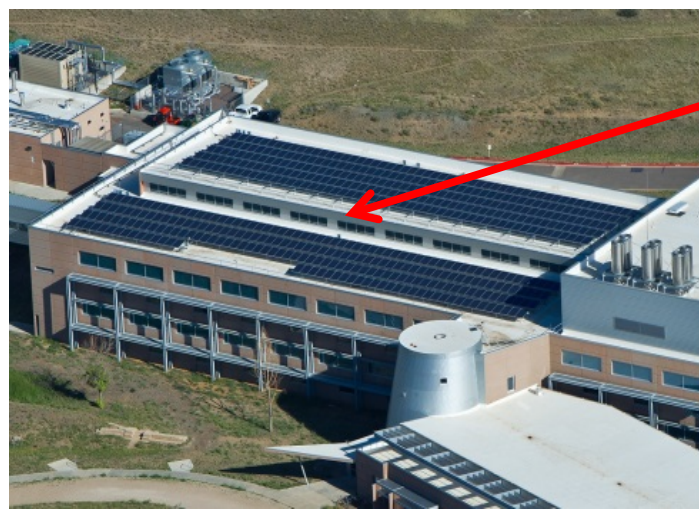

Reflections from wall not addressed

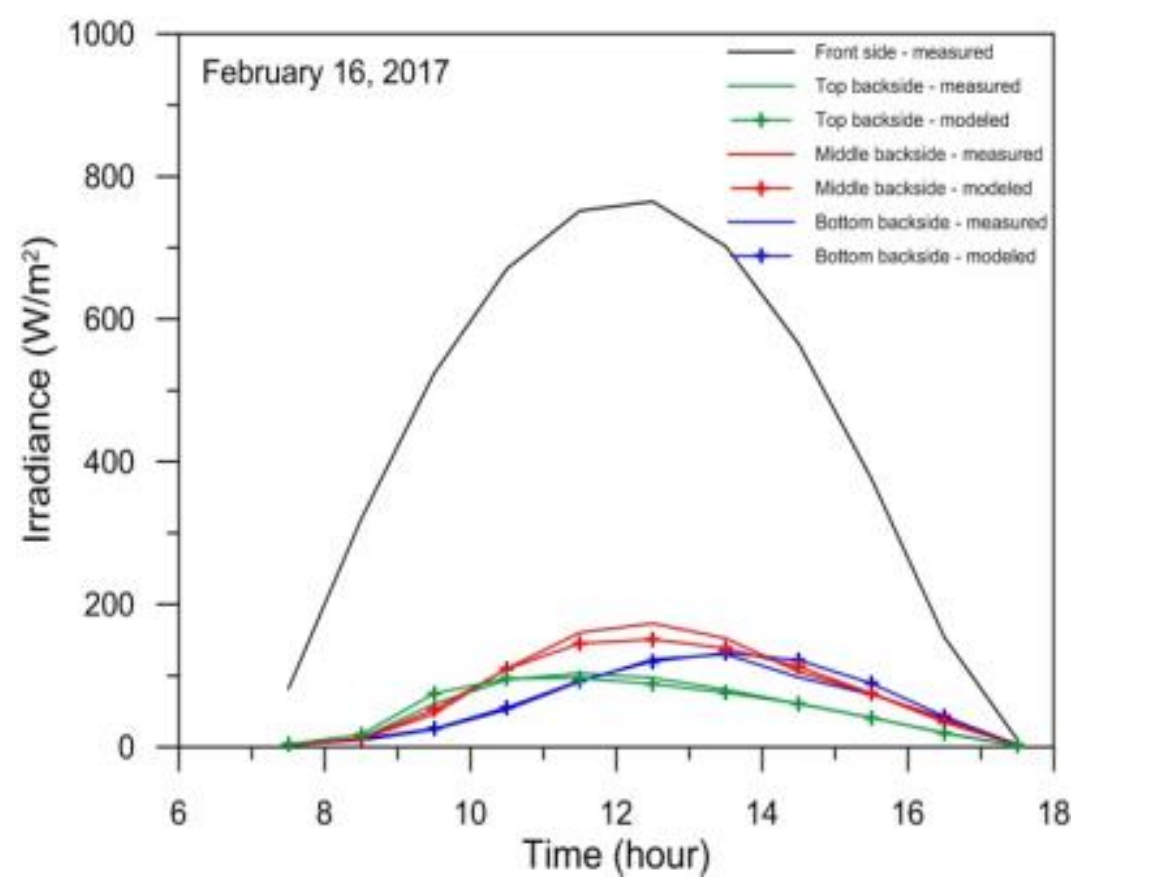

Upper Roof 


\section{Validation Results - Sandia Site}

- Data for 10/1/2016 thru 3/31/2017 - 15 minute averages.

- Mean for bottom reference cell was $10 \%$ of front side.

- Mean for top reference cell was 7\% of front side.

- Model MBD ranged from -4 to $9 \mathrm{~W} / \mathrm{m}^{2},-9$ to $16 \%$.

- Model RMSD ranged from 5 to $16 \mathrm{~W} / \mathrm{m}^{2}, 14$ to $31 \%$.


Modeled Versus Measured BSI for Top Reference Cell in $35^{\circ}$ Tilt Row 


\section{Validation Results - Sandia Site (continued)}

BSI plus front side irradiance - total irradiance to PV cell.

- Model MBD ranged from -11 to $14 \mathrm{~W} / \mathrm{m}^{2},-1.8$ to $2.4 \%$.

- Model RMSD ranged from 25 to $36 \mathrm{~W} / \mathrm{m}^{2}, 4$ to $6 \%$.


Modeled Versus Measured BSI Plus Front Side Irradiance for Top Location in $35^{\circ}$ Tilt Row 
- The backside irradiance model for bifacial PV systems uses configuration factors, and accounts of the effects of shading, restricted view of the sky, and angle-of-incidence for both beam and diffuse radiation.

- The model was validated using data from NREL and Sandia.

- The model MBD for the total irradiance available to the PV cell (BSI plus front side irradiance) was within

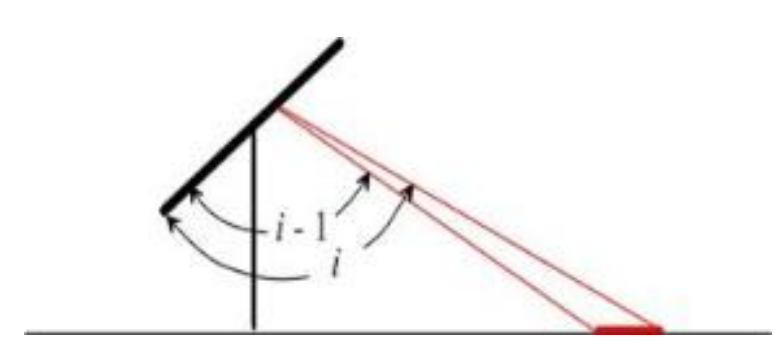
$\pm 2.5 \%$. 


\section{Questions?}

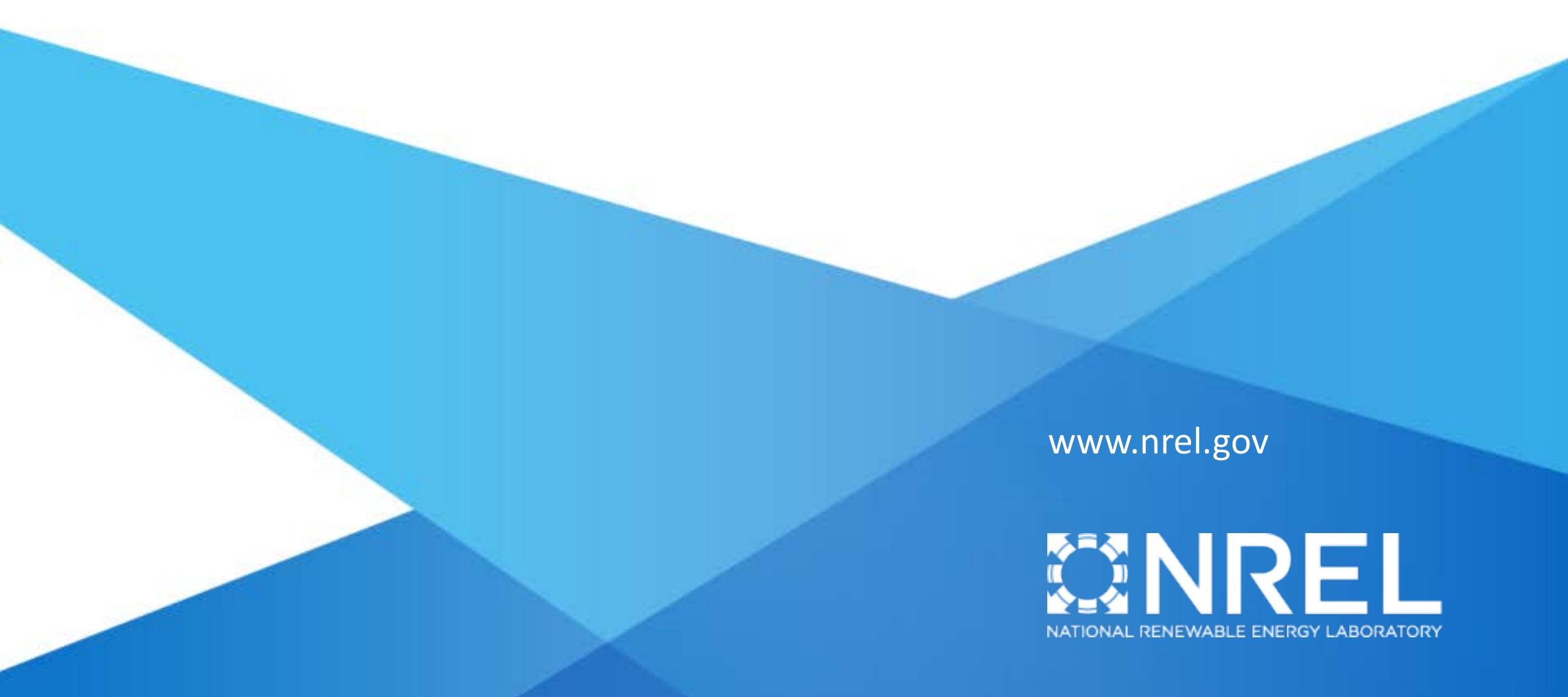

NREL is a national laboratory of the U.S. Department of Energy, Office of Energy Efficiency and Renewable Energy, operated by the Alliance for Sustainable Energy, LLC. 